\title{
Increased Synthesis of
}

\section{Phospholipid during Phagocytosis}

\author{
Peter Elsbach with the technical assistance of Susan Levy \\ From the Department of Medicine, New York University School of Medicine, \\ New York 10016
}

A B S TRACT Incorporation in vitro of ${ }^{32} \mathrm{P}$ labeled lysolecithin (LPC) or lysophosphatidylethanolamine (LPE) into respectively lecithin (PC) and phosphatidylethanolamine (PE) of rabbit granulocytes and alveolar macrophages was compared in the absence and in the presence of ingestible particles. Maximal synthesis of PC by intact cells occurred at added LPC concentrations of less than $0.05 \mathrm{mmole} /$ liter, i.e., at levels found in plasma. Accumulation of $\mathrm{PC}^{32} \mathrm{P}$ proceeded linearly for at least $30 \mathrm{~min}$ and varied directly with cell concentration. While per cell granulocytes and macrophages converted comparable amounts of medium LPC to cellular PC, per milligram of protein, the granulocytes were approximately four times more active than the much larger macrophages. After $30 \mathrm{~min}$ newly synthesized $\mathrm{PC}^{32} \mathrm{P}$ represented as much as $5 \%$ of total granulocyte PC. For macrophages this fraction did not exceed $1 \%$. Addition of polystyrene or zymosan particles to the cell suspension resulted in up to 3-fold stimulation of incorporation of $\mathrm{LPC}_{-}{ }^{32} \mathrm{P}$ or $\mathrm{LPE}-{ }^{32} \mathrm{P}$ into their respective diacyl derivatives. This stimulation did not occur when the cells were homogenized. Breakdown of LPC to water-soluble products during phagocytosis of polystyrene particles was the same as at rest. By use of doubly labeled LPC, the mechanism of $\mathrm{PC}$ synthesis by the two cell types has

This paper is part III of a series entitled "Metabolism of phospholipids by phagocytic cells," of which part I is reference 15. This work was presented in part at the 1967 meetings of the American Society for Clinical Investigation in Atlantic City (1) and at the $\mathrm{XI}^{\text {th }}$ International Conference on the Biochemistry of Lipids held in August 1967 in Jerusalem, Israel.

Received for publication 28 February 1968 and in revised form 1 May 1968. been identified as direct acylation of medium LPC, both at rest and during engulfment. Evidence presented in the case of granulocytes suggests that the increased translocation of medium LPC- ${ }^{32} \mathrm{P}$ during phagocytosis and its conversion to $\mathrm{PC}$ represents net synthesis.

The findings indicate that LPC, a normal constituent of plasma, can serve as substrate in PC synthesis by phagocytic cells. This mechanism of $\mathrm{PC}$ synthesis can account for appreciable addition of membrane PC, especially by granulocytes. It is proposed that stimulation of this pathway provides building blocks for increased membrane formation during phagocytosis.

\section{INTRODUCTION}

Ingestion of particles by phagocytic cells is accompanied by striking morphologic alterations involving both outer and intracellular membranes (2). These changes have suggested formation of new membrane. However, no convincing evidence for increased (net) synthesis of macromolecular membrane constituents has yet been obtained. Thus, leucine $-{ }^{14} \mathrm{C}$ incorporation into protein of polymorphonuclear leukocytes is not stimulated during phagocytosis (3), and labeling of phospholipids with acetate- $-{ }^{14} \mathrm{C}$ is only modestly increased $(3,4)$. Furthermore, labeling of phospholipids with ${ }^{82} \mathrm{P}$ while enhanced during engulfment of particulate matter is only significantly greater in minor phospholipid species $(5,6)$.

Recently Lands (7) and Erbland and Marinetti $(8,9)$ have demonstrated in liver homogenates that lysocompounds can be directly converted to their diacyl derivatives. It has subsequently become apparent that enzymes carrying out these 
synthetic activities occur in numerous mammalian tissues including rabbit polymorphonuclear leukocytes and alveolar macrophages (10-16). These enzymes, when concurring with phospholipases that produce lysocompounds, are considered to contribute greatly to the dynamic metabolism of cellular glycerolphosphatides (17).

Lysocompounds such as lysolecithin (LPC) and lysophosphatidylethanolamine (LPE) are normal components of plasma (18-21). The studies of Stein and Stein have shown that a considerable portion of i.v. injected radioactively labeled LPC and LPE can be recovered as lecithin (PC) and phosphatidylethanolamine (PE) in many tissues (12). Plasma lysocompounds may therefore be important precursors of cellular phosphoglycerides.

This report concerns an examination in vitro of utilization of LPC and LPE for synthesis of corresponding diacyl products by two types of phagocytic cells, polymorphonuclear leukocytes and alveolar macrophages, both obtained from rabbits. The results indicate that the conversion of medium monoacylphosphoglycerides to cellular diacyl compounds provides an appreciable source of cell lipid. During phagocytosis this conversion is markedly stimulated.

\section{METHODS}

Cells. Polymorphonuclear leukocytes were collected from sterile peritoneal exudates produced in rabbits as described before (22). After a cell count the granulocytes (more than $95 \%$ of all cells) were resuspended in Hanks' solution ${ }^{1}$ or, in some experiments, in ascitic fluid plus $20 \%$ homologous serum, to give a final cell concentration of $2 \times 10^{7}$ cells per $0.5 \mathrm{ml}$ of complete incubation mixture. This cell number corresponds to approximately $1 \mathrm{mg}$ of protein. In a number of experiments higher cell concentrations were used.

Alveolar macrophages were obtained from $\mathrm{BCG}^{2}$ treated rabbits according to the procedure of Myrvik, Leake, and Oshima (23) as modified by Cohn and Wiener (24). After a cell count the macrophages were sedimented at $100 \mathrm{~g}$ for $10 \mathrm{~min}$, the saline used for collection and washing discarded, and the cells resuspended in Hanks' solution to give a final cell concentration of $1 \times 10^{7}$ cells per $0.5 \mathrm{ml}$ of incubation mixture, corresponding to approximately $2 \mathrm{mg}$ of protein.

Homogenates of both cell types were prepared in 0.25 $\mathrm{M}$ sucrose in a glass homogenizing tube, using a motor-

1 Hanks' balanced salt solution (without phenol red), Microbiological Associates, Inc., Bethesda, Md.

${ }^{2}$ Water-washed lyophilized BCG was a gift of Dr. Z. A. Cohn of The Rockefeller University. driven teflon pestle. Homogenization of granulocytes was carried out for three periods of $30 \mathrm{sec}$. For macrophages at least three $1 \mathrm{~min}$ periods of homogenization were required for complete disruption as assessed by phasecontrast microscopy.

Radioactive substrates. $\mathrm{PC}$ and $\mathrm{PE}$ were biosynthetically labeled by incubating rat liver slices with orthophosphate ${ }^{32} \mathrm{P}^{3}$ as described in detail before $(15,16)$. The LPC- ${ }^{32} \mathrm{P}$ and LPE- ${ }^{32} \mathrm{P}$ were obtained by breakdown of the corresponding ${ }^{32} \mathrm{P}$-labeled diacylphosphatides with Crotalus adamanteus phospholipase $\mathrm{A}, 4$ also as recently reported (14). Radiochemical purity of the ${ }^{32} \mathrm{P}$ lysocompounds as determined by thin-layer chromatography on silica gel $\mathrm{G}^{5}$ (see below) was at least $98 \%$ for LPC and at least $95 \%$ for LPE.

Incubation procedure. Radioisotopically labeled LPC or LPE of known specific radioactivity in chloroform: methanol (2:1) was taken to dryness in a glass tube, and a solution of bovine albumin 6 in phosphate buffer (0.05 mole/liter, $\mathrm{pH} \mathrm{7.4)}$ or rabbit serum was added. Homogeneous dispersion of the labeled lysocompound in the protein solution was obtained by vigorous agitation on a Vortex mixer (Scientific Industries Inc., Springfield, Mass.).

The $20 \mathrm{mg}$ of bovine albumin or the $0.1 \mathrm{ml}$ of rabbit serum added to the incubation mixture contained respectively approximately 20 (16) and $10 \mathrm{~m} \mu$ moles of LPC. Ascitic fluid contained less than $5 \mathrm{~m} \mu$ moles $/ 0.5 \mathrm{ml}$. No meaningful experiment could be designed to determine whether only part or all of this LPC is available for cellular uptake. Arbitrarily, therefore, only the added LPC (from 15 to $60 \mathrm{~m} \mu$ moles) has been included in the determination of medium substrate concentration. This most likely means that all calculations of conversion of LPC to PC and glycerylphosphorylcholine (GPC) represent estimates that are too low, especially in experiments at lower added LPC levels. However, this limitation in exact quantification of conversion does not seriously affect the conclusions arrived at.

Incubation mixtures of $0.5 \mathrm{ml}$ contained $0.1 \mathrm{ml}$ of the labeled albumin solution (final albumin concentration $4 \mathrm{~g} / 100 \mathrm{ml}$ ) and usually $2 \times 10^{7}$ granulocytes or $1 \times 10^{7}$ macrophages suspended in Hanks' solution. Other additions were as indicated in the text or in the legends.

To elicit phagocytosis, three types of particles were used: (a) polystyrene latex particles of diameter $1.1 \mu ;^{7}$ (b) zymosan particles (yeast cell walls) $;^{8}$ or (c) starch granules. ${ }^{9}$ These particles were suspended in normal

${ }^{3}$ International Chemical and Nuclear Corporation, City of Industry, Calif.

${ }^{4}$ Lights and Company, Colnbrook, Bucks, England.

5 MN-Silica gel G, Brinkmann Instruments, Inc., Westbury, N. Y.

6 Armour Pharmaceutical Co., Kankakee, Ill.

7 Dow Chemical Co., Midland, Mich.

8 Fleishmann Laboratories, Standard Brands, Inc., New York.

9 A generous gift of Dr. Bernard Hofreiter of the Northern Regional Laboratory, U. S. Department of Agriculture, Peoria, Ill. 
saline. Unless stated otherwise, $0.1 \mathrm{ml}$ of the polystyrene solution, representing $3.6 \times 10^{\circ}$ particles of diameter $1.1 \mu$ or $0.025 \mathrm{ml}$ of a zymosan suspension in normal saline representing $3.5 \times 10^{7}$ particles were added to determine the effect of phagocytosis upon metabolism of lysocompounds. Preliminary experiments indicated that dialysis of polystyrene particles before use (6) did not alter the observed effects, and therefore the unmodified suspension was used. Chloroform:methanol (2:1) extracts of polystyrene particles contain only traces of lipid phosphorus, virtually none of which migrates with reference $L P C$ or LPE.

Extracts of $3.5 \times 10^{7}$ zymosan particles contain 4 m $\mu$ moles of LPC, 9 of PC, 7 of sphingomyelin, and 5 of PE. As in the case of LPC associated with albumin, the possible contribution of all or part of the LPC extractable from zymosan particles to the LPC available for cellular metabolism has been ignored.

Incubation was carried out at $37^{\circ} \mathrm{C}$ in a shaking water bath with air as the gas phase. Control samples in each experiment included reaction mixtures without cells, incubated for varying periods of time, and complete mixtures extracted before incubation $(0 \mathrm{~min})$.

Radiochemical assays. Conversion of the labeled lysocompounds to diacyl and deacylated derivatives was determined as recently described (14-16). Briefly, after the indicated incubation times biochemical activity was stopped by addition of $5 \mathrm{ml}$ of methanol and $5 \mathrm{ml}$ of chloroform (25). Extraction was then allowed to proceed overnight at room temperature. The lipid extracts were not washed with water so that water-soluble breakdown products of the ${ }^{32} \mathrm{P}$-labeled substrate were retained. After filtration and removal of the solvents under reduced pressure, the extracts were taken up in a few drops of methanol and transferred to a silica gel G thin-layer plate. The ${ }^{32} \mathrm{P}$-labeled substrates and the reaction products were separated in a solvent system consisting of chloroform:methanol:glacial acetic acid: water $(110: 56: 20: 10, \mathrm{v} / \mathrm{v})$. The separated compounds were localized by exposure to iodine vapor and by scanning with a survey meter for radioactivity 10 and were identified by comparison with appropriate reference substances. After disappearance of iodine stains, marked areas were scraped off the plate into counting vials for determination of radioactivity by liquid scintillation counting after $12 \mathrm{ml}$ of toluene containing $4.0 \mathrm{~g}$ of BBOT 11 per liter was added. Quenching due to silica gel was minimal and closely similar for each fraction since care was taken to scrape off approximately equal amounts of powder. The radioactivity in each fraction was expressed as per cent of the total radioactivity recovered in all fractions and converted to millimicromoles on the basis of the known amounts of radioactive substrate added. In most experiments the whole incubation mixture was extracted. Where indicated, cells and

10 Model 701, Lionel Electronic Laboratories, Inc., Hillside, N. J.

11 2,5-bis [2-(5-tert-butylbenzoxazolyl)] thiophene, Packard Instrument Co., Inc., Downers Grove, Ill. medium were separately extracted. In these experiments the extracts were quantitatively transferred to the thinlayer plate to permit determination of total radioactivity and extent of conversion of the monoacyl substrate to diacyl and deacylated compounds.

The radioactive water-soluble products formed during incubation with $\mathrm{LPC}-{ }^{32} \mathrm{P}$ or $\mathrm{LPE}-{ }^{32} \mathrm{P}$ were identified by established techniques $(26,27)$ as GPC and GPE. Phosphorus determination on phospholipids fractionated by thin-layer chromatography was carried out directly on the silica gel by the method of Parker and Peterson (28). Protein contents of cell suspensions and homogenates were determined by the method of Lowry, Rosebrough, Farr, and Randall (29).

Assessment of "binding" of LPC to polystyrene and zymosan particles. A small and constant amount of LPC- ${ }^{22} \mathrm{P}$ and increasing concentrations of unlabeled LPC in albumin solution $(20 \mathrm{mg}$ in $0.1 \mathrm{ml})$ were mixed in conical glass centrifuge tubes, with $0.1 \mathrm{ml}$ of polystyrene particles $\left(3.6 \times 10^{\circ}\right.$ particles of $1.1 \mu$. diameter $)$ and $0.3 \mathrm{ml}$ of Hanks' solution. The particles were sedimented by centrifugation. The supernatant fluid was removed and transferred to a counting vial. The particles were resuspended in $0.3 \mathrm{ml}$ of Hanks' solution, sedimented again, and the wash transferred to a counting vial. The remaining particles were quantitatively transferred with normal saline to a counting vial. After addition of $10 \mathrm{ml}$ of chloroform:methanol (2:1), the contents of the three vials, representing one test concentration of LPC, was taken to dryness, $12 \mathrm{ml}$ of liquid scintillation mixture in toluene added, and the samples counted.

Similar experiments were carried out with $2 \times 10^{8}$ zymosan particles, except that $0.1 \mathrm{ml}$ of rabbit serum was used in place of albumin.

\section{RESULTS}

Protection by albumin against membrane-lytic effect of LPC. Recent studies of Switzer and Eder have shown that plasma LPC occurs almost exclusively in association with albumin (20).

The importance of binding of LPC to albumin for the protection of polymorphonuclear leukocytes against the lytic properties of the lysocompound is illustrated in Table I. In the absence of albumin, even low LPC concentrations in the medium produce leakage of $\mathrm{K}^{+}$from a suspension of granulocytes. Increasing LPC concentrations result in the appearance of more $\mathrm{K}^{+}$into the medium. This evidence of damage to the cell is accompanied by morphologic signs of structural changes. Examination by phase-contrast microscopy revealed swollen cells. With higher LPC concentrations the swelling was more marked, and cell outlines became unclear until actual disintegration of cells was noted. By contrast, in the 
TABLE I

Protection by Albumin against Membrane-Lytic Effect of Lysolecithin

\begin{tabular}{ccc}
\hline & \multicolumn{2}{c}{ Medium (K+) } \\
\cline { 2 - 3 } Lysolecithin & No albumin + Albumin \\
\hline mmole/liter & \multicolumn{2}{c}{$m E q /$ liter } \\
0 & 5.0 & 4.8 \\
0.2 & 7.4 & 4.4 \\
0.4 & 8.0 & 4.6 \\
0.6 & 8.4 & 4.8 \\
1.0 & 9.0 & 7.0 \\
\hline
\end{tabular}

A fresh suspension of granulocytes in Hanks' solution was divided into 10 equal portions each containing $3 \times 10^{7}$ cells. Incubation was carried out at $37^{\circ} \mathrm{C}$ for $30 \mathrm{~min}$ in the presence of the indicated concentrations of lysolecithin (LPC), with or without $20 \mathrm{mg}$ of bovine serum albumin, in a total volume of $0.5 \mathrm{ml}$. After $20 \mathrm{~min}$ a drop of each suspension was taken for microscopic examination. After 30 min cells and medium were separated by centrifugation. The $\mathrm{K}^{+}$concentrations in the medium were determined by flame photometry.

presence of physiologic concentrations of albumin $(4 \mathrm{~g} / 100 \mathrm{ml})$ none of these changes occurred until the LPC level in the medium was $1 \mathrm{mmole} / \mathrm{liter}$. Because of these results all following experiments were carried out with albumin in the incubation mixture.

Incorporation of medium $L P C-{ }^{32} P$ complexed to albumin into $P C$ of granulocytes and macrophages. While albumin protects against the membrane-lytic properties of LPC, presumably because of complex formation between the two molecular species $(16,20)$, the apparent binding does not prevent metabolic utilization of LPC. Fig. 1 compares the formation of $\mathrm{PC}^{32} \mathrm{P}$ from albuminbound LPC as a function of time, by intact granulocytes and macrophages and by homogenates of both cell types. PC synthesis per milligram of protein is distinctly greater by intact granulocytes than by intact macrophages. Homogenates of both cell types under these experimental conditions are usually more active than whole cells. Whereas synthesis by intact cells proceeds in linear fashion for at least $30 \mathrm{~min}, \mathrm{PC}$ formation by homogenates levels off after $10 \mathrm{~min}$.

Fig. 2 shows the effect of increasing LPC concentrations on PC synthesis and further demonstrates the difference in activity between intact cells and homogenates. To fit the results in one graph, the units on the ordinate expressing PC synthesis per milligram of protein have been enlarged 10-fold as compared to Fig. 1. Both intact cell systems manifest maximal activity at low substrate concentrations. Especially at higher substrate levels PC synthesis by homogenates is far greater than by intact cells. This is particularly striking in the case of granulocyte homogenates $(15,16)$.

While relative to homogenates intact cells manifest modest $\mathrm{PC}$-forming activity, the radioactive PC formed from medium LPC represents as much as $5 \%$ of the total PC content of granulocytes (see Table VI) in $30 \mathrm{~min}$. For macrophages, which are less active per milligram of protein than the granulocytes and which contain more PC (16), the contribution of the conversion of exogenous LPC to cellular PC is less than $1 \%$ in $30 \mathrm{~min}$.

Fig. 3 shows that PC synthesis increased linearly with increasing numbers of cells.

Varying the $\mathrm{pH}$ of the incubation medium between 6.0 and 8.0 had little effect on PC synthesis by either cell type.

Effect of ingestion of particles upon incorporation of medium LPC into cell PC. Since the preceding results indicated that albumin-bound LPC constitutes an appreciable source of cell PC, especially for granulocytes, we examined the effect of phagocytosis upon utilization of medium LPC as a precursor of cellular PC.

Fig. 4 shows the mean values of at least four paired experiments at each time interval, in which incorporation of medium LPC- $^{32} \mathrm{P}$ into $\mathrm{PC}$ of granulocytes and macrophages was compared in the absence and presence of polystyrene or zymosan particles. The former are effectively taken up in a medium that contains albumin only (30). whereas engulfment of zymosan requires addition of whole serum (31). Control values for PC synthesis by granulocytes were the same in medium that contained albumin or serum, whereas macrophages formed more PC in the presence of $20 \%$ serum. Therefore, results obtained in macrophage experiments with polystyrene and zymosan particles are depicted by separate graphs. It is evident that ${ }^{32} \mathrm{P}$-labeling of $\mathrm{PC}$ is stimulated by addition of either polystyrene latex or zymosan particles. The results of these experiments are given as millimicromoles of PC synthesized per $2 \times 10^{7}$ cells. 


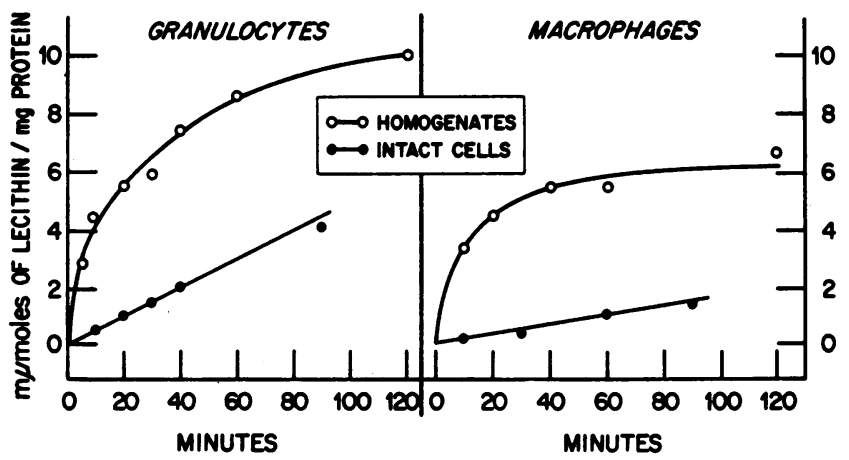

FIGURE 1 Kinetics of lecithin formation by intact and homogenized cells. Assays were carried out at $\mathrm{pH} 7.4$ and at a lysolecithin (LPC) concentration of $0.1 \mathrm{mmole} / \mathrm{liter}$, as described in Methods. Approximately equal amounts of protein were added to each incubation mixture, either as intact cells (in Hanks' solution) or as homogenate (prepared in $0.25 \mathrm{M} \mathrm{su}$ crose). Incubation mixtures containing homogenate were fortified with $2 \mu$ moles of adenosine triphosphate (ATP), $0.1 \mu$ mole of coenzyme A (CoA), $2 \mu$ moles of $\mathrm{MgCl}_{2}$, and $2.5 \mu$ moles of phosphate buffer ( $\mathrm{pH} 7.4$ ) in a total volume of $0.5 \mathrm{ml}$. Activities of homogenates were the same in phosphate buffer or in Hanks' solution. (Omission of ATP and CoA slightly reduces activity of granulocyte homogenates, but considerably reduces activity of macrophage homogenates) $)^{12}(15)$.

It may be noted that PC synthesis by an equal number of granulocytes and macrophages in the absence of particles is comparable. However, as was apparent from Figs. 1-3, PC-forming activity

12 Since optimal synthesis of lecithin (PC) by homogenates required addition of ATP and CoA, the effect of these agents on whole cells was examined. Addition of ATP and CoA in the indicated concentrations does not affect $\mathrm{PC}$ formation by intact granulocytes but stimulates intact macrophages by an average of $30 \%$ in five paired experiments (unpublished observations). In none of the experiments shown was ATP or CoA added to intact cell preparations. per milligram of protein by the much larger macrophages is about one-fourth of that by granulocytes. The extent of stimulation of PC labeling by addition of particles in individual experiments with granulocytes ranged from 25 to $100 \%$ for polystyrene and from 100 to $300 \%$ for zymosan, at time intervals of up to $60 \mathrm{~min}$. Although stimulation by both types of particles was also clearly evident in macrophage experiments, its magnitude was less than seen with granulocytes when zymosan or starch granules (Fig. 5) were used. After $30 \mathrm{~min}$ PC synthesis by granulocytes in the

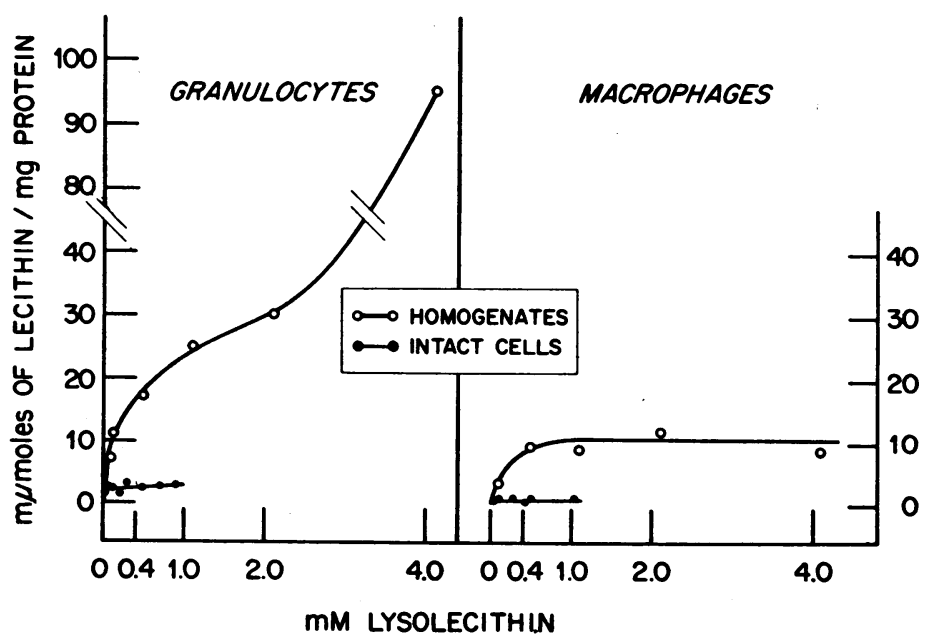

FIGURE 2 Effect of increasing lysolecithin concentrations on lecithin synthesis by intact and homogenized cells. For experimental conditions see Fig. 1. 

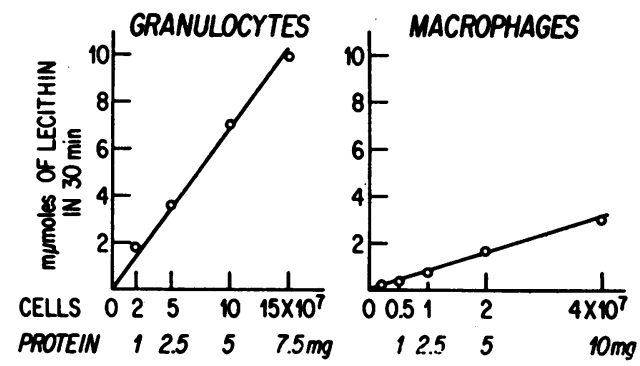

FIGURE 3 Effect of cell concentration on lecithin synthesis by intact granulocytes and macrophages. Granulocytes were incubated at an added lysolecithin (LPC) concentration of $0.05 \mathrm{mmole} / \mathrm{liter}$ and macrophages at an LPC concentration of $0.07 \mathrm{mmole} / \mathrm{liter}$.

absence of particles was $2.8 \pm 0.4$ m $\mu$ moles (mean $\pm \mathrm{SE})$ per $2 \times 10^{7}$ cells and $4.0 \pm 0.5 \mathrm{~m} \mu$ moles in the presence of polystyrene in 18 paired experiments $(P<0.01)$. These values were $3.1 \pm 1.0$ and $8.2 \pm 1.1 \mathrm{~m} \mu$ moles per $2 \times 10^{7}$ cells in five paired experiments with zymoson $(P<0.005)$. In six macrophage experiments the control values were $2.5 \pm 0.3 \mathrm{~m} \mu$ moles per $2 \times 10^{7}$ cells with albumin and $3.1 \pm 0.5$ mumoles per $2 \times 10^{7}$ cells with serum in the medium and upon addition of polystyrene or zymosan particles, $3.8 \pm 0.5$ and $4.75 \pm 0.8 \mathrm{~m} \mu$ moles per $2 \times 10^{7}$ cells respectively. These differences were not statistically significant $(P>0.05)$. However, when the values obtained in the presence of particles were expressed as per cent of control in each experiment, the $P$ value was $<0.005$ for polystyrene particles and $<0.001$ for zymosan particles.

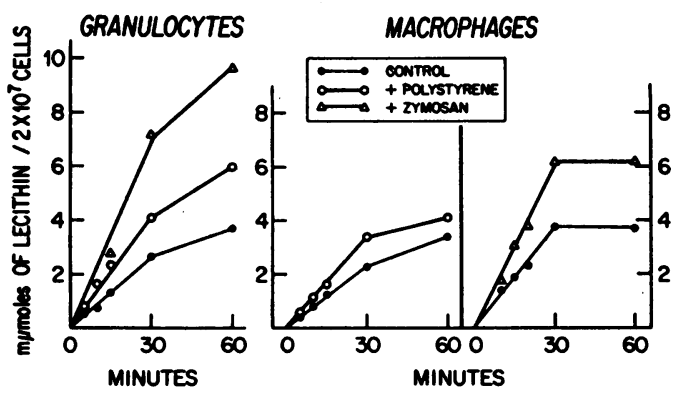

FIGURE 4 Effect of addition of particles on lecithin (PC) synthesis from medium lysolecithin. Assays and additions of particles were carried out as described in Methods. In several experiments fresh ascitic fluid was used as suspending medium instead of Hanks' solution. Since PC synthesis in these experiments fell within the same range as in experiments with Hanks' solution, results were pooled.

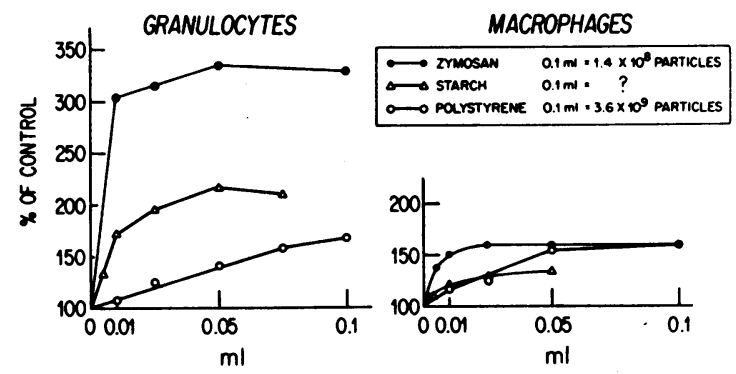

Figure 5 Effect of quantity of particles added on stimulation of lecithin synthesis. The number of starch particles per $0.1 \mathrm{ml}$ (representing $10 \mathrm{mg}$ of dry material) could not be accurately assessed because of marked heterogeneity in size.

The effect of increasing numbers of particles upon stimulation of incorporation of LPC- ${ }^{32} \mathrm{P}$ to $\mathrm{PC}$ is shown in Fig. 5. Results are given as per cent of control values after incubation for $30 \mathrm{~min}$. Unlike polystyrene particles, the much larger zymosan granules elicited a nearly maximal stimulatory effect at concentrations as low as $1.4 \times 10^{7}$ particles $(0.01 \mathrm{ml})$.

In contrast to the reproducible increase in conversion of medium LPC into cellular PC during phagocytosis, concomitant breakdown of LPC to water-soluble GPC is not enhanced upon addition of polystyrene particles (Fig. 6).

On the other hand incorporation of another monoacylphosphoglyceride, namely $\mathrm{LPE}-{ }^{32} \mathrm{P}$, into its diacyl derivative by both cell types is stimulated during incubation with polystyrene particles (Fig. 7).

Verification of actual phagocytosis of the polystyrene particles was obtained by electron microscopy of thin sections of granulocytes incubated under the usual experimental conditions for 15

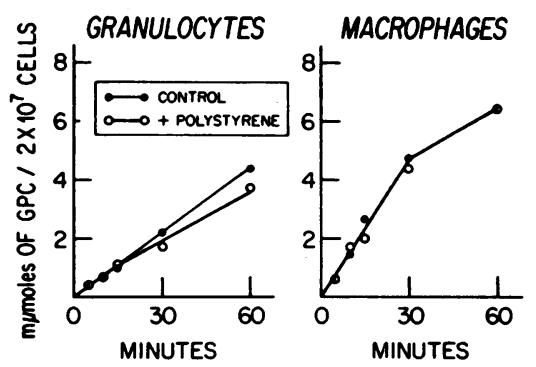

FIGURE 6 Formation of glycerylphosphorylcholine $(G P C)$ from medium lysolecithin in the presence and absence of particles. The results represent the means of at least four paired experiments at each time interval. 


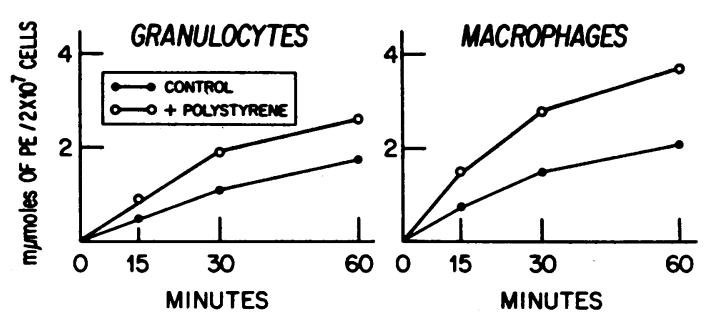

FIGURE 7 Synthesis of phosphatidylethanolamine $(P E)$ from medium lysophosphatidylethanolamine (LPE) with and without particles. Results are means of two closely similar experiments carried out with granulocytes at LPE concentrations of 0.07 and $0.12 \mathrm{mmole} / \mathrm{liter}$ and of three macrophage experiments at LPE concentrations of $0.04,0.06$, and $0.1 \mathrm{mmole} / \mathrm{liter}$.

min. Intracellular localization of polystyrene particles, surrounded by a membrane-like structure, was readily apparent. ${ }^{13}$

Addition of particles to the cell suspension might in some manner change the physicochemical properties of substrate and (or) enzyme to produce the observed stimulation. If this were so, addition of particles may be expected to stimulate PC synthesis by homogenates. Table II shows that, in contrast to the reproducible stimulation of PC synthesis by intact cells, homogenates are unaffected by addition of particles.

Further, homogenates of cells that had ingested particles were no more active than homogenates of resting cells.

$13 \mathrm{We}$ are greatly indebted to Dr. D. Zucker-Franklin who kindly performed the electron microscopy.

TABLE II

Effect of Addition of Particles upon Lecithin Synthesis by Intact Granulocytes and Homogenized Cells

\begin{tabular}{ccc}
\hline & + Polystyrene & + Zymosan \\
\hline Intact cells & $153 \pm 6.5$ & $313 \pm 43$ \\
& $(18)$ & $(5)$ \\
Homogenates & $103 \pm 3.9$ & 107 \\
& $(10)$ & \\
\hline
\end{tabular}

Suspensions of intact granulocytes in Hanks' solution and freshly prepared homogenates were incubated for $30 \mathrm{~min}$ with $3.6 \times 10^{9}$ polystyrene particles or with $3.5 \times 10^{7}$ zymosan particles. Synthesis of lecithin (PC) was assayed as described in Methods. The results are given as per cent of control values in each experiment. The values listed are means $\pm \mathrm{SE}$ of the indicated number of experiments $(n)$. Homogenization in $0.25 \mathrm{M}$ sucrose or in Hanks' solution gave the same results.
Studies on the nature of increased incorporation of medium LPC- ${ }^{82} \mathrm{P}$ into cellular PC during engulfment of particles

Adsorption of LPC to polystyrene and zymosan particles. If $\mathrm{LPC}-{ }^{32} \mathrm{P}$ were adsorbed to the particles, increased labeling of $\mathrm{PC}$ might reflect increased entry of LPC along with engulfed particles. Fig. $8 a$ shows that increasing concentrations of added LPC result in a linear increase in the quantity of LPC associated with particles washed free of medium (see Methods). This association is distinctly greater for zymosan than for polystyrene particles. Fig. $8 b$ depicts a similar experiment carried out at one LPC concentration $(0.075$ mmole/liter) but with a varying number of zymosan particles. It demonstrates a linear increase in "binding" with an increasing number of particles.

The extent of "binding" by the usual number of polystyrene particles $\left(3.6 \times 10^{9}\right)$ and of zymosan particles $\left(3.5 \times 10^{7}\right)$ introduced to each incubation mixture is less than 2 m $\mu$ moles at the LPC concentration range used in these experiments (0.03-0.12 mmole/liter). Since only a limited portion of the added particles is engulfed during incubation (32), increased delivery of substrate during phagocytosis through "binding" of the LPC to ingested particles can only account for a fraction of the observed stimulation of PC synthesis (even if it is assumed that the adsorbed LPC is available to cellular enzymes). Moreover, several experiments were carried out with up to $10^{8}$ cells per incubation mixture instead of the usual $2 \times 10^{7}$ granulocytes or $1 \times 10^{7}$ macrophages. Under these conditions the absolute increase in PC formation in the presence of particles far exceeded the amount adsorbed, since both PC
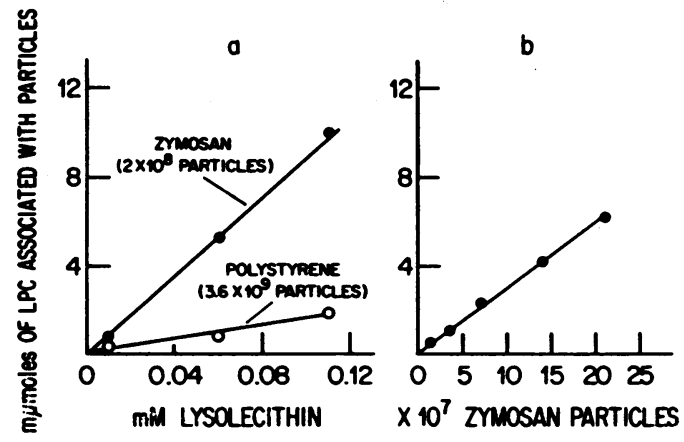

FIGURE 8 "Binding" of lysolecithin- $\mathrm{P}$ to particles. The experiment was carried out as described in Methods. 
synthesis and its stimulation in the presence of particles increased proportionately with increasing cell number.

Biochemical mechanism of $P C$ formation from medium LPC by granulocytes. In mammalian tissues LPC can be directly converted to PC in two ways: (a) by acylation of LPC according to the pathway of Lands $(7)$, or $(b)$ by a transfer reaction in which one LPC molecule donates its fatty acid to another $\operatorname{LPC}(8,9,13-15)$. Current evidence suggests that LPE does not serve as substrate in such a transfer reaction, and that the conversion of LPE to PE occurs only as a result of direct acylation (16). Previous studies in this laboratory have indicated that homogenates of polymorphonuclear leukocytes contain enzymes of both pathways, whereas in macrophage homogenates conclusive evidence was obtained only for the operation of pathway $a(14-16)$.

With a mixture of palmitic acid-1-14 $\mathrm{C}$-labeled LPC and $\mathrm{LPC}^{32} \mathrm{P}$, it can be determined which of the two pathways mainly accounts for synthesis of PC. If insertion of an unlabeled fatty acid by acylation represents the mechanism of PC synthesis, the ${ }^{14} \mathrm{C} /{ }^{32} \mathrm{P}$ ratio in the newly formed $\mathrm{PC}$ and in the LPC substrate should remain the same. On the other hand, in the transfer reaction a fatty acid $-1-{ }^{14} \mathrm{C}$ from LPC occupies the free $-\mathrm{OH}$ group, resulting in ${ }^{14} \mathrm{C} /{ }^{32} \mathrm{P}$ ratio in $\mathrm{PC}$ formed twice that of LPC. Intermediate values for ${ }^{14} \mathrm{C} /{ }^{32} \mathrm{P}$ may be expected if both pathways operate simultaneously.

Table III shows the results of such an experiment. The addition of polystyrene particles resulted in the usual stimulation of PC synthesis. The ${ }^{14} \mathrm{C} /{ }^{32} \mathrm{P}$ ratio in the $\mathrm{PC}$ formed by the granulocytes and in the LPC substrate remained the same, both in the absence and presence of particles. These findings indicate that direct acylation accounts for synthesis, and that the observed stimulation is not due to appreciable additional operation of the transfer reaction.

Evidence that increased labeling of $P C$ by granulocytes during phagocytosis represents net increase of cellular PC. Increased labeling of PC by incorporation of medium LPC-32. $\mathrm{P}$ in the presence of particles need not represent net addition of cellular PC if newly labeled PC is released into the medium, or if increased conversion of $\mathrm{LPC}^{-32} \mathrm{P}$
TABLE III

Incorporation of Radioactivity from Lysolecithin Labeled with ${ }^{14} \mathrm{C}$ and ${ }^{32} P$ into Lecithin of Granulocytes Incubated with or without Particles

\begin{tabular}{lccc}
\hline & & & $\begin{array}{c}{ }^{14} \mathrm{C} /{ }^{22} \mathrm{P} \text { in } \\
\text { lecithin }\end{array}$ \\
\cline { 3 - 4 } & Time & $\begin{array}{c}\text { Lecithin } \\
\text { formed }\end{array}$ & $\begin{array}{c}{ }^{14} \mathrm{C} /{ }^{22} \mathrm{P} \text { in } \\
\text { lysolecithin }\end{array}$ \\
\hline \multirow{4}{*}{ Control } & min & $\begin{array}{c}\text { mumoles } / \mathrm{mg} \\
\text { protein }\end{array}$ \\
& 30 & 4.85 & 1.15 \\
+ Polystyrene & 60 & 7.4 & 1.06 \\
& 30 & 7.2 & 1.05 \\
& 60 & 15.0 & 0.96 \\
\hline
\end{tabular}

Suspensions of granulocytes $\left(5 \times 10^{7}\right.$ cells/tube) in Hanks' solution were incubated with a mixture of palmitic acid-1${ }^{14} \mathrm{C}$-labeled lysolecithin (LPC) and LPC-32P (total LPC content $150 \mathrm{~m} \mu$ moles in $0.5 \mathrm{ml}$ of incubation mixture) in the absence or presence of $3.6 \times 10^{9}$ polystyrene particles. Labeling of LPC with palmitic acid-1 ${ }^{14} \mathrm{C}$ and determination of ${ }^{14} \mathrm{C}$ and ${ }^{32} \mathrm{P}$ radioactivity in $\mathrm{LPC}$ and lecithin (PC) were carried out as previously described $(14,15)$.

to PC is matched by increased degradation of PC. To examine these possibilities, experiments were carried out with both cell types. Since the relative contribution of medium LPC to formation of cellular PC is substantially greater for granulocytes than for macrophages, it could be predicted that results of experiments on granulocytes would be more conclusive. This turned out to be the case, and therefore emphasis will be placed in this section on the data obtained with granulocytes.

Table IV shows that during incubation of granulocytes for $1 \mathrm{hr}$ the accumulating $\mathrm{PC}^{32} \mathrm{P}$ remains associated with the cells, both in the absence and presence of polystyrene particles.

TABLE IV

Association of Newly Synthesized Lecithin-32P with Granulocytes

\begin{tabular}{|c|c|c|c|c|}
\hline \multirow[b]{2}{*}{ Time } & \multicolumn{2}{|c|}{ Cells } & \multicolumn{2}{|c|}{ Medium } \\
\hline & Control & $\begin{array}{l}\text { + Poly- } \\
\text { styrene }\end{array}$ & Control & $\begin{array}{l}\text { + Poly- } \\
\text { styrene }\end{array}$ \\
\hline $\min$ & \multicolumn{4}{|c|}{ mumoles of lecithin } \\
\hline 10 & 0.9 & 2.2 & 0.1 & 0.1 \\
\hline 30 & 2.8 & 5.8 & 0.1 & 0.1 \\
\hline 60 & 6.2 & 8.5 & 0.1 & 0.1 \\
\hline
\end{tabular}

Granulocytes $\left(2.5 \times 10^{7}\right.$ cells/tube $)$ were incubated with or without polystyrene particles. At the end of the indicated incubation times cells and medium were separated by centrifugation and each extracted (see Methods). 
To examine degradation of cellular PC, this phosphatide was labeled during preincubation of granulocytes for $1 \mathrm{hr}$ with LPC-82 $\mathrm{P}$ of high specific activity (Table V). In this experiment the lipid extracts were washed with water so that compounds such as GPC were not recovered. However, total counts in cells and medium were roughly comparable for all portions, indicating that no appreciable loss had taken place. It is further evident that the radioactivity in cellular PC, expressed as per cent of total counts, does not decrease during reincubation for $1 \mathrm{hr}$, even in the presence of zymosan particles. In fact, in this and other similar experiments, a slight increase in PC radioactivity was noted in the presence of particles, matched by a small decrease in LPC radioactivity in the medium. By contrast, cellular LPC radioactivity remained about the same with and without particles. These findings indicate that under the experimental conditions employed no detectable degradation of granulocyte $\mathrm{PC}^{32} \mathrm{P}$ takes place during $1 \mathrm{hr}$.

Phosphorus determinations on major phospholipid fractions of granulocytes incubated with and without particles for $0 \mathrm{~min}$ or for periods from
TABLE V

Radioactivity in Lecithin and Lysolecithin of Granulocytes and Medium upon Reincubation of Prelabeled Cells

\begin{tabular}{|c|c|c|c|c|c|}
\hline \multirow{2}{*}{$\begin{array}{l}\text { Reincubation } \\
\text { time }\end{array}$} & \multirow{2}{*}{$\begin{array}{l}\text { Total cpm } \\
\text { recovered }\end{array}$} & \multicolumn{2}{|c|}{ Lecithin } & \multicolumn{2}{|c|}{ Lysolecithin } \\
\hline & & Cells & Medium & Cells & Medium \\
\hline $\min$ & & \multicolumn{4}{|c|}{$\%$ of total cpm } \\
\hline 0 & 9550 & 84.7 & 1.9 & 5.5 & 5.7 \\
\hline 15 & 9520 & 85.6 & 0.9 & 2.8 & 8.9 \\
\hline 30 & 9950 & 86.2 & 1.0 & 2.8 & 8.3 \\
\hline $30+$ zymosan & 9515 & 87.2 & 0.7 & 3.3 & 6.4 \\
\hline 60 & 9625 & 86.0 & 0.9 & 3.2 & 7.1 \\
\hline $60+$ zymosan & 10,765 & 89.6 & 0.7 & 2.9 & 4.3 \\
\hline
\end{tabular}

Preincubation of $6 \times 10^{8}$ granulocytes was carried out for $60 \mathrm{~min}$ in $0.5 \mathrm{ml}$ of ascitic fluid containing $200,000 \mathrm{cpm}$ of LPC- ${ }^{3} \mathrm{P}$ representing $100 \mathrm{~m} \mu$ moles. At the end of this period the cells were sedimented by centrifugation for $10 \mathrm{~min}$ at $100 \mathrm{~g}$; the supernatant radioactive medium was removed and the cell pellet rinsed twice with nonradioactive ascitic fluid. The cells were then resuspended in ascitic fluid in a total volume of $1.8 \mathrm{ml}$. This suspension was equally distributed over six tubes each of which contained $0.2 \mathrm{ml}$ of homologous serum and, where indicated, $1.4 \times 10^{8} \mathrm{zymo-}$ san particles in $0.1 \mathrm{ml}$ saline. After the indicated times of reincubation cells and medium were separated by centrifugation and each extracted in chloroform; methanol $(2: 1, v / v)$. The extracts were washed twice with $7 \mathrm{~mm}$ $\mathrm{CaCl}_{2}$ and quantitatively transferred to thin-layer plates (see Methods).

TABLE VI

Major Phospholipid Fractions of Granulocytes Incubated with and without Particles

\begin{tabular}{|c|c|c|c|c|c|}
\hline & Incubation time & LPC & SPH & PC & $\mathrm{PE}$ \\
\hline \multirow{3}{*}{ Control } & $\min$ & & mumol & & \\
\hline & 0 & $\begin{array}{l}7.5 \pm 1.5 \\
(10)\end{array}$ & $\begin{array}{c}41.4 \pm 3.7 \\
\text { (9) }\end{array}$ & $\begin{array}{l}55.5 \pm 1.8 \\
\quad(10)\end{array}$ & $\begin{array}{c}31.5 \pm 3.0 \\
(8)\end{array}$ \\
\hline & $15-60$ & $\begin{array}{l}6.0 \pm 1.0 \\
(20)\end{array}$ & $\begin{array}{l}40.5 \pm 3.1 \\
\quad(16)\end{array}$ & $\begin{array}{l}56.5 \pm 1.8 \\
\quad(20)\end{array}$ & $\begin{array}{c}33.0 \pm 1.4 \\
\quad(15)\end{array}$ \\
\hline \multirow[t]{2}{*}{+ Polystyrene } & 0 & $\begin{array}{c}10.0 \pm 1.3 \\
\quad(7)\end{array}$ & $\begin{array}{c}43.8 \pm 5.6 \\
\quad(6)\end{array}$ & $\begin{array}{c}56.3 \pm 3.0 \\
(5)\end{array}$ & $\begin{array}{c}37.0 \pm 2.2 \\
(7)\end{array}$ \\
\hline & $15-60$ & $\begin{array}{l}8.1 \pm 1.2 \\
\quad(13)\end{array}$ & $\begin{array}{l}45.0 \pm 4.4 \\
\quad(12)\end{array}$ & $\begin{array}{l}53.7 \pm 2.3 \\
\quad(13)\end{array}$ & $\begin{array}{l}38.0 \pm 2.2 \\
\quad(13)\end{array}$ \\
\hline \multirow[t]{2}{*}{+ Zymosan } & 0 & $\begin{array}{c}8.2 \pm 2.9 \\
(4)\end{array}$ & $\begin{array}{l}36.0 \pm 2.3 \\
\quad(3)\end{array}$ & $\begin{array}{c}58.0 \pm 5.7 \\
(4)\end{array}$ & $\begin{array}{c}32.0 \pm 7.5 \\
\text { (3) }\end{array}$ \\
\hline & $15-60$ & $\begin{array}{l}9.0 \pm 1.3 \\
\quad(11)\end{array}$ & $\begin{array}{l}34.1 \pm 1.4 \\
\quad(10)\end{array}$ & $\begin{array}{l}54.7 \pm 2.1 \\
\quad(11)\end{array}$ & $\begin{array}{c}31.7 \pm 2.2 \\
(9)\end{array}$ \\
\hline
\end{tabular}

LPC, lysolecithin; SPH, sphingomyelin; PC, lecithin; PE, phosphatidylethanolamine. Washed lipid extracts of granulocytes were fractionated by thin-layer chromatography, and lipid phosphorus determinations were carried out on the major phospholipid species separated. LPC, SPH, PC, and PE comprised from 70 to $80 \%$ of the total lipid phosphorus applied to the plate. No attempt was made to recover other phospholipid species. Results are given as mean $\pm \mathrm{SE}$ and fall in the same range as those recently reported for homogenates of granulocytes (16). 
15 to 60 min revealed no major changes ${ }^{14}$ (Table VI).

We conclude from the evidence thus far available that the transfer of $\mathrm{LPC}-{ }^{32} \mathrm{P}$ from medium to cell PC not only represents net translocation of lipid from medium to cells, but also that the stimulation of conversion observed during phagocytosis by granulocytes reflects net addition of PC.

\section{DISCUSSION}

Previous investigations in this laboratory have demonstrated in homogenates of granulocytes and macrophages the presence of enzymes of a diacylmonoacylphosphatide cycle $(14-16,33)$. Such a cycle has been found in a number of mammalian tissues $(10,34)$ and explains that the fatty acids of glycerolphosphatides have a more rapid turnover than the glycerolphosphate backbone (17). The operation of the cycle implies that lysocompounds are produced during phospholipid turnover, and that the level of these naturally occurring membrane lytic agents can be regulated not only by their further degradation to GPC by ubiquitous lysolecithinases, but also by their utilization for the resynthesis of important membrane constituents. While the reconversion of monoacylphosphatide, derived from metabolism of native phospholipids, to the diacyl derivatives cannot give rise to net synthesis of phospholipid, exogenous LPC and LPE, if available as precursors for synthesis of cellular PC and PE, do provide a source of new membrane lipids.

The present in vitro studies carried out with intact cells indicate that LPC and LPE complexed to albumin in the incubation medium indeed serve as substrates in the synthesis of appreciable quantities of phospholipid by granulocytes, and, to a lesser extent, by alveolar macrophages.

Lysocompounds represent a small but significant portion of the circulating phospholipids (18, $19,24)$. The virtually exclusive association of LPC with albumin in the plasma has been reported by Switzer and Eder (20). Intravenous administration of isotopically labeled LPC and

\footnotetext{
14 We have no explanation for the higher values for $\mathrm{PE}$ and the somewhat lower values for sphingomyelin found respectively in the presence of polystyrene particles and zymosan particles, regardless of incubation time. These differences with respect to control values were not statistically significant.
}

LPE is followed by rapid removal from the circulation (12), and the studies of Glomset have revealed a mechanism for repletion of LPC by the enzymatic reaction in serum: $\mathrm{PC}+$ cholesterol $\rightarrow$ LPC + cholesterol ester (35). This evidence of rapid turnover in the circulation further suggests the importance of lysocompounds in cellular phospholipid and membrane metabolism. It is therefore of particular interest that ingestion of particles is associated with a distinct stimulation of $\mathrm{PC}$ and $\mathrm{PE}$ formation from their respective lysoderivatives in the medium. These two glycerolphosphatides represent major phospholipids of both granulocytes and macrophages. The nature of the process of phagocytosis appears to require assembly of new membrane for replacement of portions of the outer membrane that served in the formation of phagocytic vacuoles.

Previous studies concerned with examining synthesis of lipid at rest and during phagocytosis have employed a number of radioactively labeled precursors. In experiments with granulocytes increased labeling of lipid during phagocytosis has been found with acetate- ${ }^{14} \mathrm{C}(3,4)$, uniformly labeled glucose- ${ }^{14} \mathrm{C}(3)$, orthophosphate- ${ }^{32} \mathrm{P}(5)$, and inositol-2- ${ }^{3} \mathrm{H} \cdot(6)$, but not with glycerolphosphate- $\alpha^{-32} \mathrm{P}(6)$ or fatty $\operatorname{acid}-{ }^{14} \mathrm{C}(6,36)$. The characteristics of labeling with acetate- ${ }^{14} \mathrm{C}$ were consistent with chain elongation of preexisting fatty acids, rather than indicative of de novo synthesis (4). A recent report further indicates that acetyl-CoA carboxylase is indeed not demonstrable in homogenates of mixed human leukocytes from peripheral blood (37). Thus. maintenance of lipid content and composition in granulocytes must depend chiefly on utilization of exogenous lipid constituents. As shown previously, granulocytes actively incorporate long-chain free fatty acids into both neutral lipid and phospholipid, a finding which suggests operation of the phosphatidic acid pathway $(36,38)$. This operation is also suggested by incorporation of orthophosphate- ${ }^{32} \mathrm{P}$ into a wide spectrum of phosphatides $(5,6)$. However, the increased incorporation during phagocytosis of orthophosphate- ${ }^{32} \mathrm{P}$ into phospholipids is restricted to minor acidic phospholipid components of granulocytes $(5,6)$, and its relevance to increased synthesis of membrane lipids seems doubtful. 
In studies on macrophages moreover, no stimulation has been observed of incorporation of acetate- ${ }^{14} \mathrm{C}$ or orthophosphate- ${ }^{32} \mathrm{P}$ into lipids during engulfment of particles (30).

These essentially negative findings left enexplained where the phagocytizing cell derives the structural components for the presumed increased membrane synthesis. We would like to raise the intriguing possibility that the enhanced incorporation during phagocytosis of compounds such as LPC into the quantitatively and metabolically more important membrane lipids may account for formation of new membrane. Since the conversion of monoacyl to diacylglycerolphosphatide involves a single biochemical step, the extent of conversion can be reasonably accurately assessed.

Evidence has been presented suggesting that increased incorporation by granulocytes of medium LPC-32 P into PC reflects net addition of phospholipid. This conclusion is based upon the following findings: $(a)$ while increased labeling of cellular PC took place during incubation with particles, no labeled PC appeared in the medium, indicating that newly synthesized PC remains associated with the cells (Table IV). This finding is in accord with previous experiments in which granulocyte lipids were labeled with acetate $-{ }^{14} \mathrm{C}$ (4) or with fatty acid-14C $(36)$; (b) no demonstrable breakdown of prelabeled PC of granulocytes occurred during reincubation for $1 \mathrm{hr}$, either in the presence or in the absence of particles (Table V).

While the stimulation of incorporation of medium lysocompounds into PC and PE of macrophages during incubation with particles is comparable to that observed in granulocytes, its significance in terms of net addition of lipid is more difficult to assess. In $30 \mathrm{~min}$ PC synthesis from medium LPC usually is less than $1 \%$ of the PC content of macrophages, even during phagocytosis. Current, as yet unpublished, studies indicate appreciable turnover of prelabeled $P C-{ }^{32} \mathrm{P}$ in the same period. It cannot be reliably ascertained therefore whether or not the increased labeling of PC represents net addition of PC molecules.

The mechanism of synthesis of diacylphosphoglycerides from LPC and LPE by intact granulocytes and macrophages is direct acylation. In homogenates of granulocytes, but not of macro- phages, evidence for an additional pathway of synthesis of PC from LPC has been recently presented $(14,15)$. This reaction in which LPE does not appear to be a substrate (16) consists of transfer of the fatty acid from one LPC molecule to another, resulting in formation of $\mathrm{PC}$ and GPC (7, 8, 12-17). The results shown in Table III indicate that formation of $\mathrm{PC}$ by intact granulocytes both at rest and during phagocytosis is entirely accounted for by the acylation pathway of Lands (7). Thus, in contrast to findings in homogenates, experiments with intact granulocytes, in line with other studies of whole tissues (12), provide no evidence of operation of the transfer reaction.

Since acylation of lysocompounds requires free fatty acid and since incorporation of medium free fatty acid- ${ }^{14} \mathrm{C}$ into lipids of granulocytes is not stimulated during phagocytosis $(6,36)$, another source of fatty acid than that present in the medium must be available. Preliminary experiments suggest that increased hydrolysis of granulocyte triglycerides during phagocytosis provides the fatty acid necessary for enhanced acylation of lysocompounds.

Our present results do not allow any conclusion concerning the location of the enzymes concerned with LPC metabolism. The particulate nature of monoacylglycerolphosphatide acylase has been established in several tissues $(7,9,15)$. It has been proposed that lysolecithinase activity of artery tissue and mouse ascites tumor cells may be associated with the outer cellular membrane $(39,40)$. In view of the cell-damaging properties of lysocompounds the hypothesis seems attractive that conversion of these substances by acylation to important membrane constituents and by hydrolysis to nonlytic end products may also occur on or in the cell surface, rather than requiring passage in unmodified form through the membrane followed by intracellular metabolism. The finding that LPC acylase and lysolecithinase activities of erythrocytes after hemolysis remain confined to washed ghosts (41-43) may support this contention. Such outer membrane associated enzymatic activities in other cells would provide a protective mechanism against local harmful concentrations of lysocompounds, and, in the case of phagocytosis which initially involves primarily 
changes in the outer membrane, a ready means of adding building blocks for new membrane synthesis.

Further studies to explore these possibilities must await more satisfactory techniques for obtaining reasonable yields of pure outer membrane fractions without loss of enzymatic activity and the preparation of ${ }^{8} \mathrm{H}$-labeled monoacylglycerolphosphatides of high enough specific activity to allow thin-section radioautography of cells in various stages of functional activity.

\section{ACKNOWLEDGMENTS}

This work is supported by a grant from the United States Public Health Service (AM 05472). Dr. Elsbach is a Career Scientist of the Health Research Council of the City of New York (Contract I-379).

\section{REFERENCES}

1. Elsbach, P. 1967. Stimulation of lecithin synthesis from medium lysolecithin during phagocytosis. $J$. Clin. Invest. 46: 1052. (Abstr.)

2. Zucker-Franklin, D., and J. G. Hirsch. 1964. Electron microscope studies on the degranulation of rabbit peritoneal leukocytes during phagocytosis. $J$. Exptl. Med. 120: 569.

3. Sbarra, A. J., and M. L. Karnovsky. 1960. The biochemical basis of phagocytosis. II. Incorporation of $\mathrm{C}^{14}$-labeled building blocks into lipid, protein, and glycogen of leukocytes during phagocytosis. J. Biol. Chem. 235: 2224.

4. Elsbach, P. 1959. Composition and synthesis of lipids in resting and phagocytizing leukocytes. J. Exptl. Med. 110: 969 .

5. Karnovsky, M. L., and D. F. Hoelzl Wallach. 1961. The metabolic basis of phagocytosis. III. Incorporation of inorganic phosphate into various classes of phosphatides during phagocytosis. J. Biol. Chem. 236: 1895.

6. Sastry, P. S., and L. E. Hokin. 1966. Studies on the role of phospholipids in phagocytosis. J. Biol. Chem. $241: 3354$.

7. Lands, W. E. M. 1960. Metabolism of glycerolipids. II. The enzymatic acylation of lysolecithin. J. Biol. Chem. 235: 2233.

8. Erbland, J. F., and G. V. Marinetti. 1965. The enzymatic acylation and hydrolysis of lysolecithin. Biochim. Biophys. Acta. 106: 128.

9. Erbland, J. F., and G. V. Marinetti. 1965. The metabolism of lysolecithin in rat-liver particulate systems. Biochem. Biophys. Acta. 106: 139.

10. Webster, G. R. 1965. The acylation of lysophosphatides with long-chain fatty acids by rat brain and other tissues. Biochim. Biophys. Acta. 98: 512.

11. Stein, Y., O. Stein, and B. Shapiro. 1963. Enzymatic pathways of glyceride and phospholipid synthesis in aortic homogenates. Biochim. Biophys. Acta. 70: 33.
12. Stein, Y., and O. Stein. 1966. Metabolism of labeled lysolecithin, lysophosphatidyl ethanolamine and lecithin in the rat. Biochim. Biophys. Acta. 116: 95.

13. Mulder, E., J. W. O. van den Berg, and L. L. M. van Deenen. 1965. Metabolism of red-cell lipids. II. Conversions of lysophosphoglycerides. Biochim. Biophys. Acta. 106: 118

14. Elsbach, P., J. W. O. van den Berg, H. Van den Bosch, and L. L. M. van Deenen. 1965. Metabolism of phospholipids by polymorphonuclear leukocytes. Biochim. Biophys. Acta. 106: 338.

15. Elsbach, P. 1966. Phospholipid metabolism by phagocytic cells. I. A comparison of conversion of ${ }^{32} \mathrm{P}$ lysolecithin to lecithin and glycerylphosphorylcholine by homogenates of rabbit polymorphonuclear leukocytes and alveolar macrophages. Biochim. Biophys. Acta. 125: 510.

16. Elsbach, P. 1967. Metabolism of lysophosphatidyl ethanolamine and lysophosphatidyl choline by homogenates of rabbit polymorphonuclear leukocytes and alveolar macrophages. J. Lipid Res. 8: 359.

17. van Deenen, L. L. M. 1965. Phospholipids and biomembranes. In Progress in the Chemistry of Fats and Other Lipids. R. T. Holman, editor. Pergamon Press, Inc., New York.

18. Phillips, G. B. 1957. The isolation of lysolecithin from human serum. Proc. Natl. Acad. Sci. U. S. 43: 566.

19. Newman, H. A. I., Ching-Tong Liu, and D. B. Zilversmit. 1961. Evidence for the physiological occurrence of lysolecithin rat plasma. J. Lipid Res. 2: 403.

20. Switzer, S., and H. A. Eder. 1965. Transport of lysolecithin by albumin in human and rat plasma. J. Lipid Res. 6: 506.

21. Misra, U. K. 1965. Isolation of lysophosphatidylethanolamine from human serum. Biochim. Biophys. Acta. 106: 371.

22. Elsbach, P., and I. L. Schwartz. 1959. Studies on the sodium and potassium transport in rabbit polymorphonuclear leukocytes. J. Gen. Physiol. 42: 883.

23. Myrvik, Q. N., E. S. Leake, and S. Oshima. 1962. A study of macrophages and epithelioid-like cells from granulomatous (BCG-induced) lungs of rabbits. J. Immunol. 89: 745 .

24. Cohn, A. Z., and E. Wiener. 1963. The particulate hydrolases of macrophages. I. Comparative enzymology, isolation and properties. J. Exptl. Med. 118: 991.

25. Bligh, E. S., and W. J. Dyer. 1959. A rapid method of total lipid extraction and purification. Can. J. Biochem. Physiol. 37 : 911.

26. Olley, J., and R. M. C. Dawson. 1956. Paper chromatography of hydrolysis products of phospholipids. Biochem. J. 62: 5P.

27. Dawson, R. M. C. 1960. A hydrolytic procedure for the identification and estimation of individual phospholipids in biological samples. Biochem. J. 75: 45.

28. Parker, F., and N. F. Peterson. 1965. Quantitative analysis of phospholipids and phospholipid fatty acids from silica gel thin-layer chromatograms. J. Lipid Res. 6: 455. 
29. Lowry, O. H., N. J. Rosebrough, A. L. Farr, and R. J. Randall. 1951. Protein measurement with the Folin phenol reagent. J. Biol. Chem. 193: 265.

30. Oren, R., A. E. Farnham, K. Saito, E. Milofsky, and M. L. Karnovsky. 1963. Metabolic patterns in three types of phagocytizing cells. J. Cell Biol. 17: 487.

31. Hirsch, J. G., and Z. A. Cohn. 1960. Degranulation of polymorphonuclear leucocytes following phagocytosis of microorganisms. J. Exptl. Med. 112: 1005.

32. Roberts, J., and J. H. Quastel. 1963. Particle uptake by polymorphonuclear leucocytes and Ehrlich ascitescarcinoma cells. Biochem. J. 89: 150.

33. Elsbach, P., and M. A. Rizack. 1963. Acid lipase and phospholipase activity in homogenates of rabbit polymorphonuclear leukocytes. Am. J. Physiol. 205: 1154.

34. Scow, R. O., Y. Stein, and O. Stein. 1967. Incorporation of dietary lecithin and lysolecithin into lymph chylomicrons in the rat. J. Biol. Chem. 242: 4919.

35. Glomset, J. A. 1962. The mechanism of the plasma cholesterol esterification reaction: plasma fatty acid transferase. Biochim. Biophys. Acta. 65: 128.

36. Elsbach, P. 1963. Incorporation of $1{ }^{14} \mathrm{C}$ linoleic acid into lipids of polymorphonuclear leukocytes. Biochim. Biophys. Acta. 70: 157.
37. Majerus, P. W., and R. Laskara. 1967. Fatty acid biosynthesis in human leukocytes. J. Clin. Invest. 46: 1596.

38. Elsbach, P. 1964. Comparison of uptake of palmitic, stearic, oleic and linoleic acid by polymorphonuclear leukocytes. Biochim. Biophys. Acta. 84: 8.

39. Eisenberg, S., Y. Stein, and O. Stein. 1967. The role of lysolecithin in phospholipid metabolism of human umbilical and dog carotid arteries. Biochim. Biophys. Acta. 137: 221.

40. Stein, O., and Y. Stein. 1967. Utilization of lysolecithin by Landschütz ascites tumor in vivo and in vitro. Biochim. Biophys. Acta. 137: 232.

41. Oliveira, M. M., and M. Vaughan. 1964. Incorporation of fatty acids into phospholipids of erythrocyte membranes. J. Lipid Res. 5: 156.

42. Mulder, E., and L. L. M. van Deenen. 1965. Metabolism of red-cell lipids. III. Pathways of phospholipid renewal. Biochim. Biophys. Acta. 106: 348.

43. Munder, P. G., E. Ferber, and H. Fisher. 1965. Untersuchungen über die Abhängigkeit der cytolytischen Wirkung des Lysolecithins von Membranenzymen. Z. Naturforsch. 20: 1048. 